\title{
Fear of COVID-19 in High School Personnel: a Survey Study in Western Mexico
}

\author{
Gabino Cervantes-Guevara ${ }^{1,2}$ - Manuel Maciel-Saldierna ${ }^{3}$. \\ Emmanuel Elizondo-Hernández ${ }^{3}$. Lorena Alejandra Cervantes-Pérez ${ }^{4}$. \\ Guillermo Alonso Cervantes-Cardona ${ }^{5}$ - Bejanmín García-Reyna ${ }^{1}$. \\ Juan Carlos Ibarrola-Peña ${ }^{6}$ - Yolanda Lorelei Almanza-Mena ${ }^{6}$. \\ Francisco José Barbosa-Camacho ${ }^{6} \cdot$ Clotilde Fuentes-Orozco $^{6}$. \\ Jonathan Matias Chejfec-Ciociano ${ }^{6}$ - José Aldo Guzmán-Barba ${ }^{6}$. \\ Paola Flores-Becerril ${ }^{6}$ • Emilio Alberto Reyes-Elizalde ${ }^{6} \cdot$ Alejandro González-Ojeda $^{6}$
}

Accepted: 15 December 2020 /Published online: 25 January 2021

(C) The Author(s), under exclusive licence to Springer Science+Business Media, LLC part of Springer Nature 2021

\section{Background}

Since December 2019, when the World Health Organization (WHO) announced a new viral pneumonia that had originated in China (Lee 2020), governments have been forced to carry out strategies to respond, adapt, and overcome obstacles, creating programs to guarantee security and social and economic stability.

In Mexico, the official announcement of the first infected patient was on February 29, 2020 (Méndez-Arriaga 2020). Thereafter, the Mexican government has implemented strategies to combat COVID-19 and prevent its spread. One such strategy was to close those industries, corporations, and workplaces that were not considered essential, resulting in thousands of industries having to improvise ways to continue operating. One of these was the education

Alejandro González-Ojeda

avygail5@gmail.com

1 Centro Universitario del Norte, Universidad de Guadalajara, Colotlan, Jalisco, Mexico

2 Hospital Civil de Guadalajara "Fray Antonio Alcalde", Universidad de Guadalajara, Guadalajara, Jalisco, México

3 Secundaria 56 Mixta "Juana de Asbaje", Secretaría de Educación Jalisco, Guadalajara, Jalisco, Mexico

4 Unidad de Trasplante de Medula Ósea, Instituto Nacional de Cancerología, Ciudad de México, México

5 Departamento de Disciplinas Filosófico, Metodológicas e Instrumentales, Centro Universitario de Ciencias de la Salud, Universidad de Guadalajara, Guadalajara, Jalisco, Mexico

6 Unidad de Investigación Biomédica 02, Hospital de Especialidades del Centro Médico Nacional de Occidente, Instituto Mexicano del Seguro Social, Belisario Domínguez 1000 Col. Independencia, Guadalajara, Jalisco, Mexico 
sector. The UN Educational, Scientific and Cultural Organization estimates that 107 countries had school activities closed by March 12, 2020, with another 29 more countries added in the following weeks (Viner et al. 2020). On March 18, 2020, the Mexican Health Secretariat reported that a total of 250,656 COVID-19 cases were expected in the country (this amounts to roughly a $0.19 \%$ of the total population of Mexico estimated around 130.8 million in 2018) (Acuña-Zegarra et al. 2020). In November 2020, the official website of the Mexican government reported 1,289,336 cases in total in his country, of which 61,631 are active and a total of 121,734 deaths (Secretaría de Salud 2020). In Mexico, face-to-face classes were suspended in March 2020 (Redacción 2020). Subsequently, continued provision of education in the different public and private academic institutes has been one of the main challenges in the pandemic.

This can be a challenge for teachers, particularly for those who have not worked previously with online platforms such as Skype, Google, or Zoom. For the many high school teachers in Mexico who are not familiar with these tools, learning to use them in ordinary circumstances would be stressful. Learning to use them while going through a pandemic and being quarantined could become chaotic, frustrating, and maddening. Moreover, widespread outbreaks of infectious diseases, such as COVID-19, are associated with psychological distress and symptoms of mental illness (Rajkumar 2020) and an increasing incidence of depression, anxiety disorder, and mental illness (Garcia-Priego et al. 2020).

Stress is pervasive among teachers in public and private schools and is usually amplified in situations where job demands are usually high and resources low. High levels of concern in teachers could translate to poor performance in classes and school activities, resulting in a lack of learning by their students. There have been relatively few investigations on the factors that contribute to this stress; private and public school teachers tend to self-evaluate or self-report the consequences of stress and burnout rather than using validated scores (Shen et al. 2015). Many factors can contribute to this phenomenon, including changing the classroom and academic program to an online platform (Arvidsson et al. 2019; Bottiani et al. 2019).

\section{Methods}

\section{Aims}

The aims were to identify the level of fear of COVID-19 in a high school personnel working in the region of Guadalajara and to determine any differences in levels according to gender, age group, and working category.

\section{Design}

This was a cross-sectional survey study that evaluated the fear of COVID-19 using the Spanish language validated version of the Fear of COVID-19 Scale (FCV-19S) (Huarcaya-Victoria et al. 2020). In addition, we asked about the participants' gender, age, and working category.

\section{Instrument}

The FCV-19S is a questionnaire that evaluates fear of the global pandemic caused by SARSCoV-2. The instrument consists of seven items, each with a 5-point Likert scale of options. 
The participant must choose the options that best represent their perception about the statements presented. Total scores range from 7 (no fear) to 35 points (highest level of fear).

\section{Participants}

The study was performed in a public high school in Guadalajara, Mexico, from June to August 2020. The study included a total of 1529 teachers and administrative personnel of a high school in the vicinity of the authors; the total population of personnel of the high school is 1800 persons, resulting in a response rate of $84.94 \%$. The researchers asked the participants for their participation, and after consenting, a physical copy of the survey was provided, to be answered anonymously. Participants were encouraged to pass the invitation to other staff members to obtain a snowball sampling method. Once completed, the surveys were collected.

\section{Data Analysis}

The data were analyzed using SPSS software (version 23.0 for Windows; IBM SPSS, Armonk, NY, USA). The descriptive analyses included proportions, means, and standard deviations. The inferential analysis of categorical variables was performed using the chisquared test, Fisher's exact probability test, or analyses of variance (ANOVA) as appropriate. Student's $t$ test was used to analyze continuous variables. Post hoc analysis was conducted with Tukey and Bonferroni tests. A probability level of $p<0.05$ was considered significant. The internal reliability of the scale was good, with a Cronbach's alpha of 0.917 .

\section{Results}

Participant demographics are described in Table 1. The mean global FCV-19S score was $20.44 \pm 6.92$, and the results according to sex, age groups, and job are also described in Table 1. An independent sample $t$ test was conducted to compare the FCV-19S mean scores

Table 1 Participants' demographic characteristics and FCV-19S mean scores

\begin{tabular}{lcc}
\hline & $n(\%)$ & FCV-19S mean scores \\
\hline Gender & & \\
Female & $864(56.5 \%)$ & $21.07 \pm 6.82$ \\
Male & $665(43.5 \%)$ & $19.62 \pm 6.96$ \\
Age groups & & \\
18-25 years & $37(2.4 \%)$ & $19.81 \pm 6.54$ \\
$26-30$ years & $124(8.1 \%)$ & $20.10 \pm 7.35$ \\
$31-35$ years & $221(14.5 \%)$ & $20.63 \pm 6.77$ \\
$36-40$ years & $216(14.1 \%)$ & $20.70 \pm 7.20$ \\
$41-45$ years & $258(16.9 \%)$ & $21.29 \pm 7.17$ \\
$46-50$ years & $216(14.1 \%)$ & $20.71 \pm 6.40$ \\
$51-55$ years & $220(14.4 \%)$ & $19.28 \pm 6.74$ \\
$56-60$ years & $134(8.8 \%)$ & $20.78 \pm 6.83$ \\
$61-65$ years & $85(5.6 \%)$ & $19.79 \pm 7.00$ \\
$66+$ years & $18(1.2 \%)$ & $17.56 \pm 6.35$ \\
Job category & $1148(75.1 \%)$ & $20.49 \pm 6.97$ \\
Teachers & $381(24.9 \%)$ & $20.28 \pm 6.77$ \\
Administrative personnel & & \\
\hline
\end{tabular}


for female $(21.07 \pm 6.82)$ and male personnel $(19.62 \pm 6.96)$, finding statistically significant differences $(t(1527)=4.07, p<0.001)$. There were no significant differences between the mean scores for teachers $(20.49 \pm 6.97)$ and administrative personnel $(20.28 \pm 6.77)$ $(t(1527)=0.51, p>0.05)$. We divided the sample into two age groups: $18-45$ years and $46-$ $66+$ years. There was no significant difference in mean FCV-19S score between the 18 45 years $(20.74 \pm 7.08)$ and $46-66+$ years groups $(20.05 \pm 6.70)(t(1527)=1.91, p>0.05)$. An ANOVA test performed to compare the mean scores of all the age groups did not show any significant differences $(F(9,1519=1.74, p>0.05)$.

\section{Emotional and Physical Responses to Fear}

We compared the emotional and physical responses to fear between male and female personnel using items 1, 2, and 4 to evaluate the emotional responses to fear and items 3, 5, 6, and 7 to evaluate physical responses to fear. An independent samples $t$ test was conducted to compare the emotional response mean scores for female personnel $(10.25 \pm 3.0)$ and male personnel $(9.73 \pm 3.17)$, finding statistically significant differences $(t(1527)=3.30, p<0.001)$. A comparison of the emotional response mean scores for teachers $(10.03 \pm 3.11)$ and administrative personnel $(10.02 \pm 3.04)$ did not show any significant differences $(t(1527)=0.06, p>0.05)$. Comparison of the physical responses to fear between female $(10.80 \pm 4.22)$ and male personnel $(9.88 \pm 4.24)$ showed statistically significant differences $(t(1527)=4.19, p<0.001)$. There were no significant differences between the physical response mean scores for teachers $(10.45 \pm$ $4.30)$ and for administrative personnel $(10.25 \pm 4.23)(t(1527)=0.78, p>0.05)$.

When comparing the emotional responses mean scores for the 18-45 years group (10.15 \pm $3.12)$ and the 46-66+ years group $(9.86 \pm 3.06)$, the difference was not statistically significant $(t(1527)=1.81, p>0.05)$. Likewise, the differences between the physical responses mean scores for the $18-45$ years group $(10.57 \pm 4.39)$ and the $46-66+$ years group $(10.18 \pm 4.12)$ were not statistically significant $(t(1527)=1.77, p>0.05)$.

A detailed description of emotional and physical responses, compared between genders, age groups, and job categories, can be found in Table 2.

Finally, we performed an ANOVA test to compare all the age groups' emotional responses mean scores; it did not show any significant differences. On the other hand, there was a significant effect of age on the physical responses mean scores $(F(9,1519)=2.237, p=0.018)$.

Table 2 Comparison of emotional and physical responses to fear between genders, age groups, and job categories

\begin{tabular}{|c|c|c|c|c|}
\hline & \multicolumn{4}{|l|}{ Fear responses } \\
\hline & Emotional response & $t$ scores & Physical response & $t$ scores \\
\hline \multicolumn{5}{|l|}{ Gender } \\
\hline Female & $10.25 \pm 3.0$ & $3.30 * * *$ & $10.80 \pm 4.22$ & $4.19 * * *$ \\
\hline Male & $9.73 \pm 3.17$ & & $9.88 \pm 4.24$ & \\
\hline \multicolumn{5}{|l|}{ Age groups } \\
\hline $18-45$ years & $10.15 \pm 3.12$ & 1.81 & $10.57 \pm 4.39$ & 1.77 \\
\hline $45-66+$ years & $9.86 \pm 3.06$ & & $10.18 \pm 4.12$ & \\
\hline \multicolumn{5}{|l|}{ Job category } \\
\hline Teachers & $10.03 \pm 3.11$ & 0.06 & $10.45 \pm 4.30$ & 0.78 \\
\hline Administrative personnel & $10.02 \pm 3.04$ & & $10.25 \pm 4.23$ & \\
\hline
\end{tabular}

Data presented as means and standard deviation. $t$ scores obtained by Students' $t$ test; *** $p<0.001$ 
Post hoc comparisons using the Tukey HSD test indicated that the 41-45-year age group (11 \pm $4.43)$ differed significantly from the 51-55-year group $(9.65 \pm 4.01)$. This difference was consistent after a Bonferroni test. There were no significant differences between any of the other age groups.

\section{Discussion}

The emergence of COVID-19 and its consequences has led to fears, worries, and anxiety among individuals worldwide (Ahorsu et al. 2020). Research has shown that emotions such as fear can affect their decision-making by undermining rationality; however, it can also motivate people, moderating their choices (Wagner et al. 2019).

Fear is a powerful emotion that can affect human behavior and job performance. One study on the psychological impact of quarantine in Chinese university students found that $24.9 \%$ of those interviewed experienced anxiety related to the COVID-19 outbreak (Baiano et al. 2020).

In our sample, the average global score of FCV-19S was 20.44, which implies that most people suffered from a medium to high level of fear of COVID-19. It is interesting to note that the average score in our population is higher than that of others studies reported in general population of Latin America and Russia (Barrios et al. 2020; Huarcaya-Victoria et al. 2020; Reznik et al. 2020). This could be due to the Mexican environment of neglect, high incidence of COVID-19 cases and the unclear strategies of its government, which gave a complicated picture for its population. One way to make teachers feel secure could be to let them be part of the plan against COVID-19. A study conducted in the Philippines, which asked how the teachers dealt with the pandemic, found that the most commonly used preventive measure was social distancing $(98.2 \%)$, almost $44 \%$ of teachers avoided crowded places, $20.2 \%$ observed proper hygiene, $16.5 \%$ used hand washing practices, $7.8 \%$ exercised, $6.4 \%$ wore face masks, $2.7 \%$ took vitamins, $1.4 \%$ stayed at home, and only $0.9 \%$ followed the government guidelines (Talidong and Toquero 2020).

In contrast, in a study performed in hospital personnel in the same region as this study, the level of fear is lower in healthcare professionals and overall hospital staff (Barbosa-Camacho et al. 2020; García-Reyna et al. 2020). This could be due to a greater comprehension of the disease and easier access to protective measures than the general population.

An analysis conducted in the general population of China to survey peritraumatic psychological distress during the epidemic found that scores were associated with participants' gender, age, education, occupation, and region. Female respondents showed significantly higher psychological distress than their male counterparts (mean $(\mathrm{SD})=24.87$ (15.03) vs. 21.41 (15.97), $p<0.001$ ) (Qiu et al. 2020). Multiple studies have indicated the most vulnerable groups in this pandemic to be women, college students, and older adults (Huarcaya-Victoria 2020). In concord with this, a $t$ test in our population to compare the emotional response mean scores for female personnel $(10.25 \pm 3.0)$ and male personnel $(9.73 \pm 3.17)$ found statistically significant differences $(t(1527)=3.30, p<0.001)$. This result was expected, because even without a pandemic, women tend to have higher levels of social anxiety symptoms and are diagnosed with psychological illnesses more frequently than men (Allan et al. 2017). However, a comparison of the mean scores for the 18-45 and the 46-66+ age groups found no statistically significant effect for older adults. Additionally, an ANOVA test comparing mean scores of all the age groups did not show any significant differences. Although our study found older people had the same incidences as other age groups, international literature strongly 
maintains that they are a higher risk group for psychological illness caused by isolation and pandemic-related stress. It is not only the chronological age but also the presence of chronic disease and comorbidities that make individuals more vulnerable to COVID-19 and related diseases, including psychological illness. We also know that during emergency situations, older adults with cognitive or physical impairments are at even greater risk (Ayalon et al. 2020). Elderly people are also the most likely group to suffer physical symptoms related to stress, anxiety, fear, and psychological illness. In our population, there was a significant effect of the age groups on the physical responses mean scores.

The coronavirus pandemic affected the performance and ability of teachers to give or receive information. Mexico, like most countries in the world, had to improvise to continue with school courses at all educational levels. One of the most frequently used strategies was to go to an online website to teach classes, which may have contributed to increased stress and sadness in teachers. A Spanish study exploring the feelings of physical education teachers who had to improvise in this situation found that one of the main changes in emotional state was that teachers presented as happy and smiling when they taught physical education in person and were in direct contact with the students before confinement but were sad when they had to switch to online teaching (Varea and González-Calvo 2020). It is important, therefore, to give faculty staff some flexibility, to allow them to develop their own ways to reach out to students and to assist them in this transition. With proper support and encouragement, they can all enjoy the benefits of taking the challenge created by such changes head on (Eachempati and Ramnarayan 2020).

In our sample of teachers, the average FCV-19S was $20.44 \pm 6.92$, which implies that most teachers suffered from a medium to high level of fear of COVID-19. Currently, there is limited information about the fear of COVID-19 in teachers and school administrative personnel. Talidong and Toquero (2020) conducted a study based on a 25-question survey of Filipino teachers' practices, perceptions, and experiences of the COVID-19 outbreak. They found that the greatest concern of teachers was the safety of their loved ones and that their lifestyles had been affected by fears related to the pandemic. The teachers had used various types of activities and measures, such as acquiring new hobbies, to deal with anxiety, while adhering to the preventive and educational policies of the Department of Education and the Commission on Higher Education.

A higher incidence of fear of COVID-19 is expected in those professions on the front line, such as healthcare workers who are frequently exposed to COVID-19 patients. Nevertheless, it is important to pay special attention to those educating our future professionals, because their failure may translate into an educational weakness. Teachers must be able to deliver the academic program correctly and clearly from a distance, to ensure the least risk of contagion, to manage the difficulties raised by the pandemic, and to understand how stressful and complicated social isolation can be.

The study have some limitations; one is that although we present a high number of participants, only one high school was studied; further studies should be performed including a higher diversity of educators and school personnel to better understand the impact of the pandemic in public high schools.

\section{Conclusion}

This is the first study in Mexico to evaluate fear levels in this context and population. To date, studies have only been carried out in health personnel. It is interesting to observe that the 
prevalence of fear according to the FCV-19S is higher in teaching personnel than expected. Although we found higher scores, it is necessary to continue to evaluate the consequences in the teacher-student relationship, including the performance of both parties, and to evaluate other factors that could be involved. Additionally, it is important to emphasize that female personnel reported higher scores on the FCV-19S, which is consistent with the findings of other populations and that there was a similar prevalence in all age groups. Institutions must pay special attention to those who are educating our future professionals, because their failure may translate into an educational weakness.

Authors' Contributions GCG and MMS conceived the presented idea. All authors contributed to the study conception and design. Material preparation was performed by EEH, LACP, GACP, and BGR. JAGB, PFB, and EARE assisted with the recruitment process and distribution of the surveys. Data management was performed by JCIP and YLAM. Data analysis was performed by FJBC, CFO, and AGO. All authors contributed to the writing and review of the manuscript. All authors read and approved the final manuscript.

\section{Compliance with Ethical Standards}

Conflict of Interest The authors declare that they have no conflict of interest.

Informed Consent Informed consent was obtained from all participants to be included in the study. Their privacy, confidentiality, and anonymity were ensured. All procedures followed were in accordance with the ethical standards of the National Ethics Committee and the National Scientific Research Committee authorized the study protocol with the registration number r089-5-2020 and with the Declaration of Helsinki of 1975, as revised in 2013.

\section{References}

Acuña-Zegarra, M. A., Santana-Cibrian, M., \& Velasco-Hernandez, J. X. (2020). Modeling behavioral change and COVID-19 containment in Mexico: A trade-off between lockdown and compliance. Mathematical Biosciences, 325, 108370. https://doi.org/10.1016/j.mbs.2020.108370.

Ahorsu, D. K., Lin, C., Imani, V., Saffari, M., Griffiths, M. D., \& Pakpour, A. H. (2020). The fear of COVID-19 scale: Development and initial validation. International Journal of Mental Health and Addiction, 1-9. https://doi.org/10.1007/s11469-020-00270-8.

Allan, N. P., Oglesby, M. E., Uhl, A., \& Schmidt, N. B. (2017). Cognitive risk factors explain the relations between neuroticism and social anxiety for males and females. Cognitive Behaviour Therapy, 46(3), 224 238. https://doi.org/10.1080/16506073.2016.1238503.

Arvidsson, I., Leo, U., Larsson, A., Håkansson, C., Persson, R., \& Björk, J. (2019). Burnout among school teachers: Quantitative and qualitative results from a follow-up study in southern Sweden. BMC Public Health, 19(1), 655. https://doi.org/10.1186/s12889-019-6972-1.

Ayalon, L., Chasteen, A., Diehl, M., Levy, B., Neupert, S. D., Rothermund, K., ... \& Wahl, H. W. (2020). Aging in times of the COVID-19 pandemic: Avoiding ageism and fostering intergenerational solidarity. Journals of Gerontology. Series B, Psychological Sciences \& Social Sciences, 1-4. Online ahead of print. https://doi.org/ 10.1093/geronb/gbaa051

Baiano, C., Zappullo, I., \& Conson, M. (2020). Tendency to worry and fear of mental health during Italy's COVID-19 lockdown. International Journal of Environmental Research \& Public Health, 17(16), 5928. https://doi.org/10.3390/ijerph17165928.

Barbosa-Camacho, F. J., García-Reyna, B., Cervantes-Cardona, G. A., Cervantes-Pérez, E., Chavarria-Avila, E., Pintor-Belmontes, K. J., Guzmán-Ramírez, B. G., Hernández-Bernal, A., Carlos Ibarrola-Peña, J., FuentesOrozco, C., González-Ojeda, A., \& Cervantes-Guevara, G. (2020). Comparison of Fear of COVID-19 in Medical and Nonmedical Personnel in a Public Hospital in Mexico. Research Square Repository. https:/doi. org/10.21203/rs.3.rs-37662/v1.

Barrios, I., Ríos-González, C., O’Higgins, M., González, I., García, O., Díaz, N. R., .. \& Torales, J. (2020). Psychometric properties of the Spanish version of the Fear of COVID-19 Scale (FCV-19S). 08 June 2020, PREPRINT (Version 1) available at Research Square. https://doi.org/10.21203/rs.3.rs-33345/v1 
Bottiani, J. H., Duran, C. A. K., Pas, E. T., \& Bradshaw, C. P. (2019). Teacher stress and burnout in urban middle schools: Associations with job demands, resources, and effective classroom practices. Journal of School Psychology, 77, 36-51. https://doi.org/10.1016/j.jsp.2019.10.002.

Eachempati, P., \& Ramnarayan, K. (2020). Covido-pedago-phobia. Medical Education, 54(8), 678-680. https:// doi.org/10.1111/medu.14257.

Garcia-Priego, B. A., Triana-Romero, A., Pinto-Galvez, S. M., Duran-Ramos, C., Salas-Nolasco, O., Reyes, M. M., et al. (2020). Anxiety, depression, attitudes, and internet addiction during the initial phase of the 2019 coronavirus disease (COVID-19) epidemic: A cross-sectional study in Mexico. MedRxiv, 2020(05), 10.20095844. https://doi.org/10.1101/2020.05.10.20095844.

García-Reyna, B., Castillo-García, G. D., Barbosa-Camacho, F. J., Cervantes-Cardona, G. A., Cervantes-Pérez, E., Torres-Mendoza, B. M., Fuentes-Orozco, C., Pintor-Belmontes, K. J., Guzmán-Ramírez, B. G., Hernández-Bernal, A., González-Ojeda, A., \& Cervantes-Guevara, G. (2020). Fear of COVID-19 Scale for Hospital Staff in Regional Hospitals in Mexico: a Brief Report. International Journal of Mental Health and Addiction, 19. https://doi.org/10.1007/s11469-020-00413-x.

Huarcaya-Victoria, J. (2020). Mental health considerations about the COVID-19 pandemic. Revista Peruana de Medicina Experimental y Salud Publica, 37(2), 327-334. https://doi.org/10.17843/RPMESP.2020.372. 5419.

Huarcaya-Victoria, J., Villarreal-Zegarra, D., Podestà, A., \& Luna-Cuadros, M. A. (2020). Psychometric properties of a Spanish version of the fear of COVID-19 scale in general population of Lima, Peru. International Journal of Mental Health \& Addiction, 1. https://doi.org/10.1007/s11469-020-00354-5.

Lee, S. A. (2020). Coronavirus anxiety scale: A brief mental health screener for COVID-19 related anxiety. Death Studies, 44(7), 393-401. https://doi.org/10.1080/07481187.2020.1748481.

Méndez-Arriaga, F. (2020). The temperature and regional climate effects on communitarian COVID-19 contagion in Mexico throughout phase 1. Science of the Total Environment, 735, 139560. https://doi.org/10.1016/ j.scitotenv.2020.139560.

Qiu, J., Shen, B., Zhao, M., Wang, Z., Xie, B., \& Xu, Y. (2020). A nationwide survey of psychological distress among Chinese people in the COVID-19 epidemic: Implications and policy recommendations. General Psychiatry, 33(2), 100213. https://doi.org/10.1136/gpsych-2020-100213.

Rajkumar, R. P. (2020). COVID-19 and mental health: A review of the existing literature. Asian Journal of Psychiatry, 52, 102066. https://doi.org/10.1016/j.ajp.2020.102066.

Redacción. (2020). Publica DOF acuerdo de suspensión de clases a nivel nacional por Covid-19 [DOF publishes agreement to suspend classes at the national level due to Covid-19]. La Jornada. https://www.jornada.com. mx/ultimas/sociedad/2020/03/16/publica-dof-acuerdo-de-suspension-de-clases-a-nivel-nacional-por-covid19-5707.html

Reznik, A., Gritsenko, V., Konstantinov, V., Khamenka, N., \& Isralowitz, R. (2020). COVID-19 fear in Eastern Europe: Validation of the fear of COVID-19 scale. International Journal of Mental Health \& Addiction. https://doi.org/10.1007/s11469-020-00283-3.

Secretaría de Salud (2020). COVID-19 Tablero México. [COVID-19 board Mexico] Gobierno de México. https://coronavirus.gob.mx/datos/

Shen, B., McCaughtry, N., Martin, J., Garn, A., Kulik, N., \& Fahlman, M. (2015). The relationship between teacher burnout and student motivation. British Journal of Educational Psychology, 85(4), 519-532. https:// doi.org/10.1111/bjep.12089.

Talidong, K. J. B., \& Toquero, C. M. D. (2020). Philippine teachers' practices to deal with anxiety amid COVID19. Journal of Loss \& Trauma, 25(6-7), 573-579. https://doi.org/10.1080/15325024.2020.1759225.

Varea, V., \& González-Calvo, G. (2020). Touchless classes and absent bodies: Teaching physical education in times of Covid-19. Sport, Education \& Society, 1-15. https://doi.org/10.1080/13573322.2020.1791814

Viner, R. M., Russell, S. J., Croker, H., Packer, J., Ward, J., Stansfield, C., Mytton, O., Bonell, C., \& Booy, R. (2020). School closure and management practices during coronavirus outbreaks including COVID-19: A rapid systematic review. The Lancet Child \& Adolescent Health, 4(5), 397-404. https://doi.org/10.1016/ S2352-4642(20)30095-X.

Wagner, M., Morisi, D., Wagner, M., \& Morisi, D. (2019). Anxiety, fear, and political decision making. Oxford Research Encyclopedia of Politics. Oxford University Press. https://doi.org/10.1093/acrefore/ 9780190228637.013.915.

Publisher's Note Springer Nature remains neutral with regard to jurisdictional claims in published maps and institutional affiliations. 